\title{
Cabbage Leaves: An Intervention for Breast Engorgement
}

\author{
Panneerselvam Rajaveni
}

\begin{abstract}
Motherhood is the only act that manifests in human forms the cosmic wonder of creation. Many mothers are seeking unique bonding experiences between them and their infants through breastfeeding. Breast engorgement is a painful and unpleasant condition that affects large numbers of women in the early postnatal period. About $72-85 \%$ of women are affected with breast engorgement. In India, $20 \%$ of primipara mothers are affected. Over the years, numerous strategies have been employed for the treatment of this problem such as kangaroo mother care, application of cabbage leaves, hot and cold compresses, and gentle breast massage. Cabbage leaves have both anti-irritant and antibiotic properties, which help in dilating local blood capillaries, promoting the blood supply to the breast tissues, improving milk ejection, and alleviating engorgement symptoms.

Keywords: Breast engorgement, Cabbage leaves, Intervention.

Pondicherry Journal of Nursing (2019): 10.5005/jp-journals-10084-12119
\end{abstract}

\section{INTRODUCTION}

Childbirth is a process wonderfully designed by nature, and the care provided following the birth of the baby is essential for maintaining the health of both mother and child. Many mothers are seeking unique bonding experiences between them and their infants, which is characteristics of breastfeeding and which increases maternal role attainment. ${ }^{1}$

Breastfeeding should be started within 1 hour of birth following delivery instead of waiting for several hours. Although there is only a small amount of breast milk at that time, it helps to establish feeding and maintaining a close relationship between mother and child, which is known as bonding. Breast milk is the only food of choice for infants and no other supplements are given up to 6 months. Breastfeeding offers many advantages like nutritional, immunologic, and psychological. ${ }^{2}$

The most common breast complications are breast engorgement, cracked and retracted nipple, mastitis, breast abscess, and lactation failure, leading to difficulty in breastfeeding. Breast fullness is a normal process of lactation which is accompanied by heaviness of breast, tenderness, and warmth caused by swelling of the breast tissues with blood, lymphatic fluid, and milk collected in the ducts during the process of milk production. ${ }^{3}$

When the fullness of breast is not reduced, fluid forms and swelling occurs in the breast, and it becomes hard making the skin tight and shiny. The nipple and areola may be flattened out by making the tissue difficult for the baby to grasp and become extremely tender and painful, and the mother may run a low-grade fever and become achy. ${ }^{4}$

\section{An Overview of Breast Engorgement}

Breast engorgement occurs in the mammary gland which is due to expansion and pressure exerted by the storage and synthesis of breast milk, and it usually occurs when the breasts switch from colostrum to mature milk. However, engorgement occurs when adequate milk is not expressed from the breasts. It can be aggravated by insufficient breastfeeding and due to blocked milk ducts. When the breast is engorged it may swell, throb, and cause pain from mild to extreme. ${ }^{5}$
Department of OBG Nursing, Kasturba Gandhi Nursing College, Sri Balaji Vidyapeeth Deemed University, Puducherry, India

Corresponding Author: Panneerselvam Rajaveni, Department of OBG Nursing, Kasturba Gandhi Nursing College, Sri Balaji Vidyapeeth Deemed University, Puducherry, India, Phone: +91 8056842628, e-mail: rajavenipanneerselvam94800@gmail.com

How to cite this article: Rajaveni P. Cabbage Leaves: An Intervention for Breast Engorgement. Pon J Nurs 2019;12(2):54-55.

Source of support: Nil

Conflict of interest: None

Breast engorgement occurs most commonly between third and fifth postnatal day. More than two third of women have complaints of tenderness over the breast, about $72-85 \%$ of women are affected with breast engorgement, and among these $20 \%$ of primipara mothers are affected in India. ${ }^{6}$

Breast engorgement is the most common complication occurring during the postnatal period. The most common manifestations include rise in temperature, pain and feeling of tenderness in the breasts, and generalized malaise. Severe engorgement of breast may lead to mastitis, and untreated engorgement puts pressure on the milk ducts frequently causing a plug. Breast engorgement can be prevented by feeding frequently. The mother has to feed at least 10-12 times in 24 hours or every 2 hours during the day and not more than 3 hours stretched at night. Try to feed for at least 15 to 20 minutes on the first side before giving the second. ${ }^{7}$

\section{Effect of Cabbage Leaves on Breast ENGORGEMENT}

The treatment of breast engorgement includes supporting the breast with a binder or brassiere, manual expression of any remaining milk after feed, application of cabbage leaves, hot water application, cold compression, gentle breast massage, and finally administering analgesics for pain; and the baby should be put to the breast regularly at frequent intervals. ${ }^{8}$

o The Author(s). 2019 Open Access This article is distributed under the terms of the Creative Commons Attribution 4.0 International License (https://creativecommons. org/licenses/by-nc/4.0/), which permits unrestricted use, distribution, and non-commercial reproduction in any medium, provided you give appropriate credit to the original author(s) and the source, provide a link to the Creative Commons license, and indicate if changes were made. The Creative Commons Public Domain Dedication waiver (http://creativecommons.org/publicdomain/zero/1.0/) applies to the data made available in this article, unless otherwise stated. 
Other than these, green cabbage (Brassica capitata) is used for engorgement therapy. Cabbage contains sinigrin (allylisothiocyanate) rapine, mustard oil, magnesium, oxalate, and sulfur heterosides. It helps to dilate local blood capillaries, promote blood supply to the breast tissues, and improve milk ejection. ${ }^{9}$

Cabbage leaves has both anti-irritant and antibiotic properties, which help to relieve tissue congestion and improve the flow of blood in and out of the area, allowing the body to reabsorb the fluid surrounding the breast, and also help to enhance venous and lymphatic drainage and alleviate engorgement symptoms. ${ }^{9}$

Application of green cabbage leaves to the breasts helps to reduce swelling. It should be kept inside the brassiere for 15-20 minutes in the engorged breast and should not be used more than three times per day. Discontinue the application of cabbage leaves as soon as engorgement begins to subside. Gentle massage in the breast can also help the milk flow more readily. If the nipple and areola are swollen, the mother is not supposed to feed without softening the breast. Manual expression or breast pump can be used to remove little amount of milk from the breast which in turn helps to soften the nipple and areola before feeding. ${ }^{10}$

\section{Conclusion}

Childbirth is a process wonderfully designed by nature and the care provided following the birth of the baby. Breastfeeding should be started within 1 hour of birth following delivery. Breast engorgement is a condition that occurs in the early phase of nursing. Application of cabbage leaves made from green cabbage on engorged breast to reduce swelling improves the circulation and enhances venous and lymphatic drainage, and it is also one of the natural remedies, which really works on breast engorgement.

\section{References}

1. Auerbach KG, Riordan J. Breastfeeding and Human Lactation. Sudbury, Massachusetts: Jones and Bartlett; 1998.

2. Park K. Textbook of Preventive and Social Medicine. Jabalpur: Banarsidas Bhanot Publisher; 2005.

3. Surajgupta, Sukanyanath. Motherhood and various aspects of natural child birth. Available from: http://www.Lifepositive.com.

4. Lowermilk D, Perry SE, Bobak IM. Maternity Nursing. London: Mosby Publication; 1999.

5. Santos KJS, Santana GS, Vieira TO, et al. Prevalence and factors associated with cracked nipples in the first month postpartum. BMC Pregnancy Childbirth 2016;16(1):209. DOI: 10.1186/s12884-0160999-4.

6. Gupta SP. Statistical Method. New Delhi: Sultan Chand and Sons; 2000.

7. Bobak I, Lowermilk DL, Jensen MD. Maternity Nursing. 4th ed., St. Louis Missouri: Mosby Publications; 1995.

8. Babycenter medical advisory board. Engorged breast. Available from: http:// babycenter.com.

9. Donovan D, Cabbage leaves for engorgement. Available from: http:// www.ezinearticles.com.

10. Handerson C, Jones K. Essential midwifery. London: Mosby Publication; 1997. 